\title{
IMSCI.AIMF.K
}

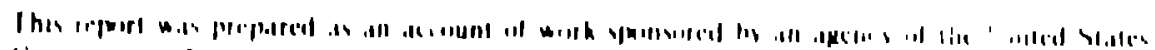

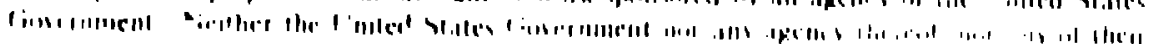

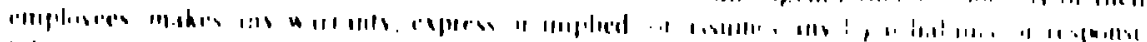

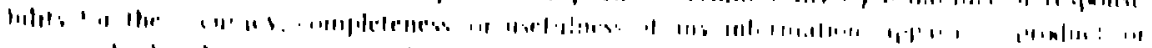

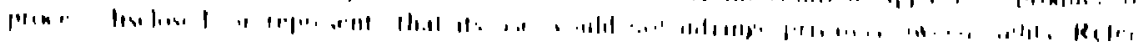

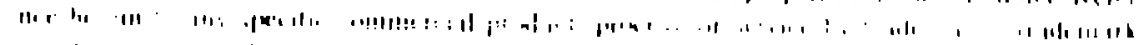

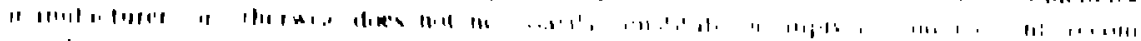

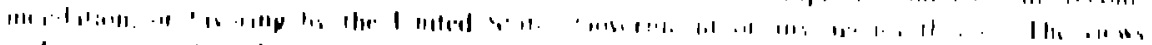

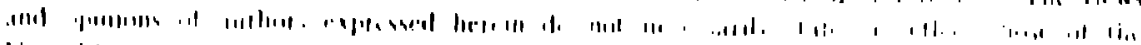

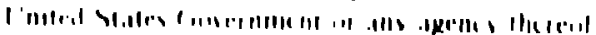




\section{SINGLE COLUMN AND TWO-COLUMN H-D-T DISTILLATION EXPERIMENTS AT TSTA}

T. Yamanishi, H. Yoshida, S. Hirata, T. Naito, and

Y. Naruse

Department of Thermonuclear Fusion Research, Japan Atomic Energy Research Institute

Tokai Research Establishment, 319-11

Tokai-mura, Ibaraki, JAPAN

292-82-5577
R. H. Sherman, J. R. Bartlit, and

J. L. Anderson

Materials Science \& Technology Division

Tritium Science \& Technology Group

Los Alamos National Laboratory, MS C348

Los Alamos, New Mexico, 87545 USA

$505 \cdot 667 \cdot 1410$

\section{ABSTRACT}

Cryogenic distillation experiments were performed at TSTA with H-D-T system by using a single column and a two-column cascade. In the single column experiment, funoamental engineering data such as the liquid holdup and the HETP were measured under a variety of operational conditions. The liquid holdup in the packed section was about $10 \sim 15 \%$ of its superficial volume. The HETP values were from 4 to $6 \mathrm{~cm}$, and increased slightly with ti,e vapor velocity. The reflux ratio had no effect on the HETP. For the two-column experiment, dynamic behavior o: the cascade was cbserved. 
1. INTRODUCTION

Separation of hydrogen isotopes by cryogenic distillation is a promising method for the mainstrcam fuel reprocessing and blanket tritium processing systems of fusion reactors. To astablish and verify design and operation methods for cryogentc distillation columns, both computer-aided simulation and experimental studies are necded. A number of simulations (1)(2) have been repurted for the cryogenic distillation columns. Although those reports produced a great deal of valuable information. the experimental datu for the cryogenic distillation columns previuusly published is stlll limited.

For the packed culumns which are used for the eryogente distllation, the HEIP (Height Equlvalent To a Theoretical Piate), the liquid holdup and the pressure drop are signiflcant parameters in column perfornance. Factors whlch are expected to have influence un these parameters are as follows: vapor velocities within the column, reflux ratios, packing materlals and phystoochemiad properlics denstly, viscoctly and surfac: tension; of flulds. Several worke:s have renurled engineerin data eje the eryogenie: distillatlon column(3)(4)(5), however, $n$ detailed discusston concerning the effect of the above-mentione factors was piven in their reports, addllionally. there are sul differences among the results wblatned and the cause of thi discrepancy has not been resulved yet. $1 t$ is also issential linis schatallun chaldefoltstlis if cascades composed uf severs coiumns are experimentally examlned. fior these reasung, furthe expritinental ibludes ale destruble. 
The most significant purpose "f the present study is to obtain iundamental englnecring data for the cryogenic distillation column and to discuss the factors affecting the column performance. For this purpuse, the HEIP, the liquid holdup and the pressurc drup were measured with the ll-D-T system as functions of the vapor velocity, the reflux ratio and the physicochemical properties of fluids by using a column in the TSTA isotope separation system. (5) As the first stage of e research prifram dealing with cascadc operatiuns, dynamic behavior (1) : wo interlinked columns was also observed under varying upel. :nal conditions in the present study. The column asscade seler : simulates a baslc configuration of that propoged by the auliavis ${ }^{(G)}$ for the blanket tritlum processing sygtems. The infurmatiun obtained from this study lmproves and conflrms the ability to predict separation characterlotics of actual-scale columns and cascades.

2. I:XIYI:RI MI:NIAL.

2. I SInkIQ: column experiment

lihe sinkla column experiment was performed with II-D and D-T systems under lotal leflux and lotal resycile modes. In the total

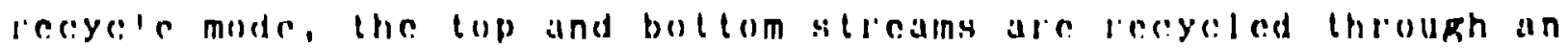

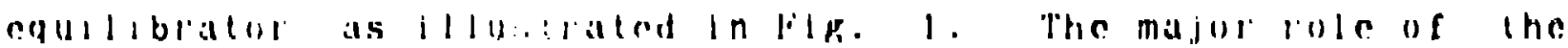

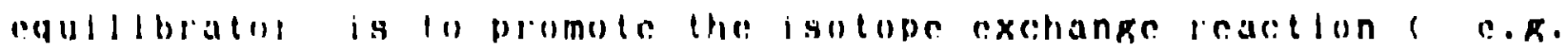

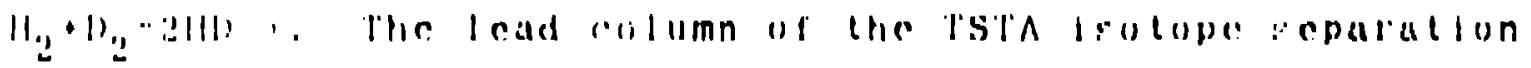


system was used in the present experiment. The specifications of the lead column are presented in Tab!e I. The refrigeration is supplied by heli:: ras, whose temperature can be luwered by a refrigerator to wouut $15 \sim 20 \mathrm{~K}$, at the condenser and the packed section. The distilation column is enclosed within a thermal radiation shield cooled by liquid nitrogen in a vacuum jacket.

The cxperimental procedure is summarized is follows. The vacuum jacket and the dlstillation column were initially evacuated, and operation of the helium refrigerator was started. Hydrugen isotupe gases were charged into the column from cylinders thrulsh an equilibrator for the H-D experiment. In the D-T experiment, uranium beds were used to supply the gases. The condensution of hydrogen isotopes occurred in the condenser and the packed section, and the liquid hydrogen thus produced fell to the reboiler. After the liquid level in the reboiler reached a speclfied value, the distillation was litiated. For the experiment with the D-T system, the hydrogen isulop: mlxture charged into the column was recycled through the equllibiator to make its composition the equilibrium state at room temperature hefore the distillation. Compostiondistributions withln the column wers miesured by ras chromatographs after the column reached strady state.

\section{2 lwo-s:ulumn rxpe::Iment}

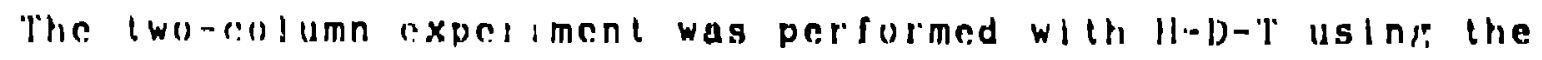

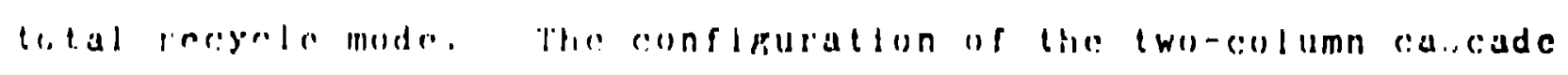
Is stiown in fity. a. the specifleatlons of the socond column are 
also presented in Table I. The general construction of the second column is the same as that of the lead column. The experiment was performed in a similar manner to that of the single column. Niter the gases were charged into the cascade, the columns were individually operated in the total reflux mode until steady state was achieved. The cascade vas then put into total recycle operation. Dynamic variation of operating parameters such as the pressures and the liquid holdups were measured while varying the reflux ratio of each column.

1 
3. Calculation of composition distribution within the column

The assumptions used in the present calculation are is follows:

(1) The column is composed of $N$ theuretical stages.

(2) The column operates adiabatically, and the molar heats ol vaporization of all components are the same.

(3) Hydrogen isotope mixture obeys Raoult's Law.

At the steady state, the component material balances a: expressed by

$$
\begin{aligned}
0= & L_{N-1} x_{i, N-1}+F_{N} i_{i, N}-\left(v_{N}+w_{N}\right) y_{i, N}-L_{N} x_{i, N}, \\
0= & v_{j+1} y_{i, j+1}-\left(L_{j}+U_{j}\right) x_{i, j}+L_{j-1} x_{i, j-1}- \\
& \left(v_{j}+w_{j}\right) y_{i, j}+F_{j} z_{i, j}, \\
0= & v_{2} y_{1,2}+F_{1} z_{i, 1}-\left(L_{1}+U_{1}\right) x_{i, 1}-v_{1} y_{1,1},
\end{aligned}
$$

where $F_{j}=$ flow rate of feed stream supplied to j-th star. $(\mathrm{mol} / \mathrm{h})$

$l_{j}=$ flow rate of liquld stream leaving J-th stage (mol/h) $N=$ number of total theoretical stages (-)

$U_{J}=$ llow rate of liquld sidestream from $J$-th stage $(\mathrm{mol} / \mathrm{h})$

$v_{j}=$ flow rate of vapor stream leaving J-th stage (mol/h)

$w_{j}=$ flow rate of vapor sidestream from j-th stage (mol/h)

$x_{i, j}=1.10$ fracilon of $i-t h$ component in the llauld stroam leaving j-th stane (-)

$y_{1.1}=$ moln fiastlun of $1-$ th componant in vapor stream 


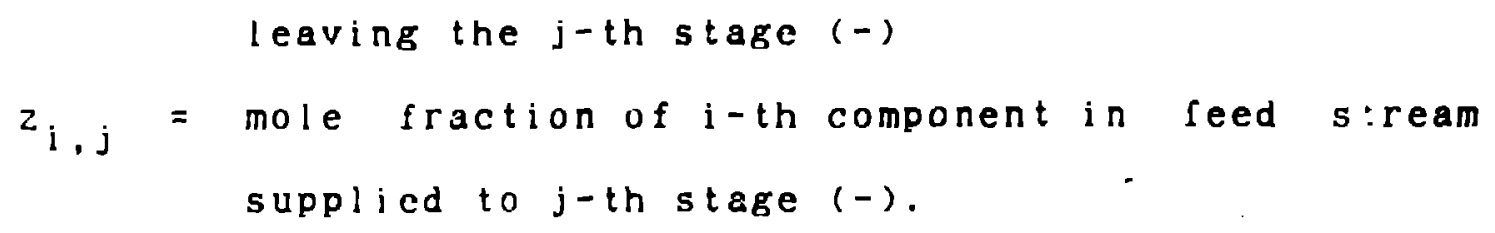

The vapor liquid equilibrium are expressed by

$y_{i, j}=F_{i}\left(T_{j}\right) x_{i, j} / P_{j}$

where $P_{j}=$ total pressure on $j-t h$ stage (Torr)

$p_{i}=$ vapor pressure of $i-t h$ component (Torr)

$T_{j}=$ temperature on $j-t h$ stage $(K)$.

If the composition of either the top or bottom stream is given, Equatin: (1) through (3) can be solved by using the vapor-1.quid relatiuns expressed by Eq. (5).

The overall HETP value is determined from the packed $h$. ight of the column and the number of total theoretical stages inich gives the best fit to experimental observations. The simple model used is sufficient to determine the onerall HETP vilue. Variation of the HETP with the column height can also be discussed by comparing experimental observations with calculational results for the composition distributlus within the column.

\section{RESLLTS AND DISCUSSION}

4.1 Pressure drop across column

$\Lambda$ strnificant regult observed is that the distillation was successfully perfurmed without column flooding as long as the 
vapor velucity. iess than $13 \mathrm{~cm} / \mathrm{sec}$. The relation between the pressure drops aus the vapor velocity is shown in Fig. 4. For the total re: ax experiment of the H-D system alone, the pressure drop is small and the loading might occur when the vapor velocily exceeds $12 \mathrm{~cm} / \mathrm{sec}$. For the other three experimental conditions, the measured values are proportional to the vapur velocity to the power $1.3 \sim 1.5$. Although a firm conclusion on this difference has not been drawn set, it may be ascribed to the hysterisis on the pressure drop. The total reflux cxperiment was performed by increasing the ilnw rates of each phase, and the column was then put into the total recycle operation. The increase of the vepor and liquid flow rates would affect wetting characteristics of the packing materials, and can possibly vary the fluidity within the columa (i.e. variations in the amount of liquid held by the packing materials and in the dispersion mechanism of the liquid falling from the concenser.). For the D-T experiment, the packing materials may be adequately wetted owing to the recycle operation performed before the disti.latiun.

\subsection{Liquid holdup within packed section}

The liquid holdup within the packed section can be evaluated by subtracting the measured value for the reboller and calculated vapor holdups of the column from the total amount of gas charged. Figure is shows the liquid holdups thus obtained under a varlety of vapor velacily conditiuns. The ubiained values, which are about $100,15 \mathrm{~mol}$. correspond to $10 \sim 15 \%$ of the 3 uperflclal volume 
of the packed section. The values for the H-D system under the total reflux experiment are slightly smaller in comparison with those of the D-T sys.. This difference appears to be due to the hysterisis discussed in the preceding section. For the other experimental conditions, no apparent difference is observed between the H-D system and the D-T system. As another significant result observed from fig. 3 , the liquid holdups for all the experimental conditions increase with the vapor velocity. For the above reasons, it can be concluded that the liquid holdup is a function of the vapor velocity.

\subsection{Effects of vapor velocity and reflux ratio on HETP}

Figure 5 shows the effect of the vapor velocity on the overall HETP values. For the total reflux mode, the values are about $45 \mathrm{~cm}$, and those of the total resycle mode are from 5 to 6 $\mathrm{cm}$. Sherman et al. (3) reported that the overall HETP values were approximately $5 \pm 0.5 \mathrm{~cm}$ for the cryogenic distillation column whose inner diameter $(0.95 \mathrm{~cm})$ and packed height $(45.7 \mathrm{~cm})$ are considerably smaller. The overall HETP values measured in the present study for the actual size column are almost equal to that obtained by sherman et al. For the total recycle mode, the separatiun performance is slightly deteriorated. Disturbance of the phase flow within the column caused by the recycle operation may result in the decrease of the vapor/liquid interfacial area. Comparing experimental results for the H-D system with those of tha D-T system, we conclude that the Dhysicochemical properties of fluids have no effect on the overall HETP value. For the 
total reflux experiment with the H-D system, the hysterisis was observed on the liqu. 'oldup and the pressure drop. However, on the overall HETP, no hysterisis is observed.

Another significant result observed from Fig. 5 is that the overall HETP values for all conditions increase slightiy with the vapor veiucity. The overall HETP value can be expressed by $(T)$ overall HETP $=z /(N-2),\left(y_{j, 1}-y_{i, N}\right)=\int_{0}^{z}\left(n_{i} / v_{j}\right) d z,-(6)$ where $n_{i}=$ mass transf :r rate for component $i$ (molm $\left.m^{2} / m^{3} h r\right)$ $z$ = packed height of column (m).

The mass transfer rate $n_{i}$ can be regarded as a function oi the vapor velocity and the column height. If $n_{i}$ increases proportionally to the vapor velocity, the overall HETP value should have no dependence on the vapor velocity. The present experimental results show that the mass transfer rate for the hydrogen isotope distillation system is proportional to less than the first power of the vapo: velocity. Wilkes (4) obtained the smaller overall HETP values $(2 \sim 3 \mathrm{~cm})$ for the cryogenic distillation culumn in the vapor veloclty range from 1 to 6 $\mathrm{cm} / \mathrm{sec}$. The difference in the vapor velocity may possibly be one of the reasons for the difference of the HETP values.

Figure o shows the effect of the reflux ratio on the overall HETP value when the vapor velocity and the flow rate of bottom stream are almost constant. The reflux ratio is varied from 8 to 35 : the top stream $\left(\sim 2 \times 10^{-3}\right.$ mol/sec) is very small in comparison with the vapor flow rate $(\sim 0.028 \mathrm{mcl} / \mathrm{sec})$. In addition, the 
increment of the liquid flow rate is only $10 \%$ of the inilial value. The overall HETP values therefore would not be affeced by the reflic. ratio, as shown in Fig.6. The reflux ratio and the vapor velocity are suitable manipulated parameters of the distillation celumn to control purities of top and buttom products at desirable values. ( 8 ) The model used in the priast study has the disadvantage that it is difflcult to consider the variation of the number of total theoretical stages $h \cdot t h$ operating conditions when dynamic behavior of the columns under control mode is simuleted. (2) How'ever, the constancy of ine overall HETP against the reflux ratio and its slight dependicy on the vapor velocity indicate that the simulation results by the stage model can be extended to actual column behavior even for the control operation.

As previously mentiuned, the overall HETP valuc as deterinlned without regard to the composltion distribution mitiln the column. Figure 7 shows the composition distribution at the steady state for a representatlve run. The calculated lincire also drawn in the flgure under the assumption that HETP 1 o constant with column helght. Table II shows the cxperlmental and calculational conditions of the run. The composilion distribution calculaled is in rough agreement. with experimental observation. The llerp depends lltle on the column helfit. The above conclusion is Important for column design: poslliuns of feed and side-cut streams of actual columng can be will catimated by the stanc model. 
4.4 Dynamic behavius of column cascade

This section will be added to the present manuscript after experimental results of the two-column are obtalned.

Figure : 1 or 2

Text : about $1 \mathrm{p}$

5. CONCLUSION

(1) In the range of the vapor veloclty to $13 \mathrm{~cm} / \mathrm{sec}$, there was no evidence that the flooding occured. The hysterisls ohso-ved 7 on the pressure drop across the column appears to be mainly related the varlation of the fluidity within the column.

(2) The liquid holdup in the packed section was approximately $10: 5 \%$ of 1 ts superf:clal volume, and Increased with vapor velocity.

(3) The measured overall HETP values were about $45 \mathrm{~cm}$ for the total reflux mode, and were $\mathrm{from} 5$ to $6 \mathrm{~cm}$ for the total lecycle mode. The overall HETr Increased sllghtly with vapor veloctly, and showed no dependence on the reflux ratlo or the physicochemical properties of the fluld. The HETP was relatlve, 'constant withln the column.

(4) The stage model is well sulted for the simulation of actual column behavior and performance.

\section{RLFFRLNCLS}

(1) J. K. BARTLIT, K. H, SMBRMAN, K. A. STUTY, and W. H. DENTON, "Hydropen lsotope Dls llllation for l'uslon lower Reaceors". 
Cryogenics, 19, 275 (1979).

(2) M. KINOSHITA, "Studies on Simulation Procedures for Stage Processes in Fusion Fuel Cycle and Distillation Systems", Doctoral Dissertation, Kyoto Unlversity (1983).

(3) J. R. BARTLIT, W. H. DENTON, and R. H. SHERMAN, "Hydrogen Isotope Distillation for the Tritlum Sygtems Test Assembly". Proc. 3rd Topl. Mtg. Technology Controlled Nucl. Fusion, Santa Fe, New Mexico, May 9-11, 1978, CONF-i80503, Vol, 2, p. 778 .

(4) W. R. Wtikes, "Tritium Waste Control: October-December 1977", MLM-2502, p. 10, Mound Laboratorles, Miamisburg, Ohlo $(1978)$.

(5) R. H. SHERMAN, J. R. BARTLIT, and D. K. VEIRS, "Experimental Results from Hydrogen/Deuterium Distlllations at the Tritlum Systems Test Assinoly", Fuston Technol, 6, 626 (1984).

(6) M. KINOSHITA, H. YOSHIDA and H. TAKESHITA, "A SImulation Study for Hydrogen lsotope Dlstillation Columns in the Tritium Breeding Blanket system of a Fusion keactor', Fusion Technol.. 10. $162(1086)$.

(7) 1. YAMANISHI, alld M. KINOSHITA, "Prellminary Experinental Study for Cryogenle Distlllation Column with Small Inner Dlameler, (II)", J. Nucl. Scl. Technol., 21, 61 (1981).

(g) M. KINOSHITA, J. H. BARTI.IT and R. H. SIIFRMAN, "Propoltional-intekral Contrul Modes for a llydragen lootope DIsll11allun Column". Nust lear Teshnol./Fuslun, s, 30 (1981). 
Table I Spicifications of distillation columns

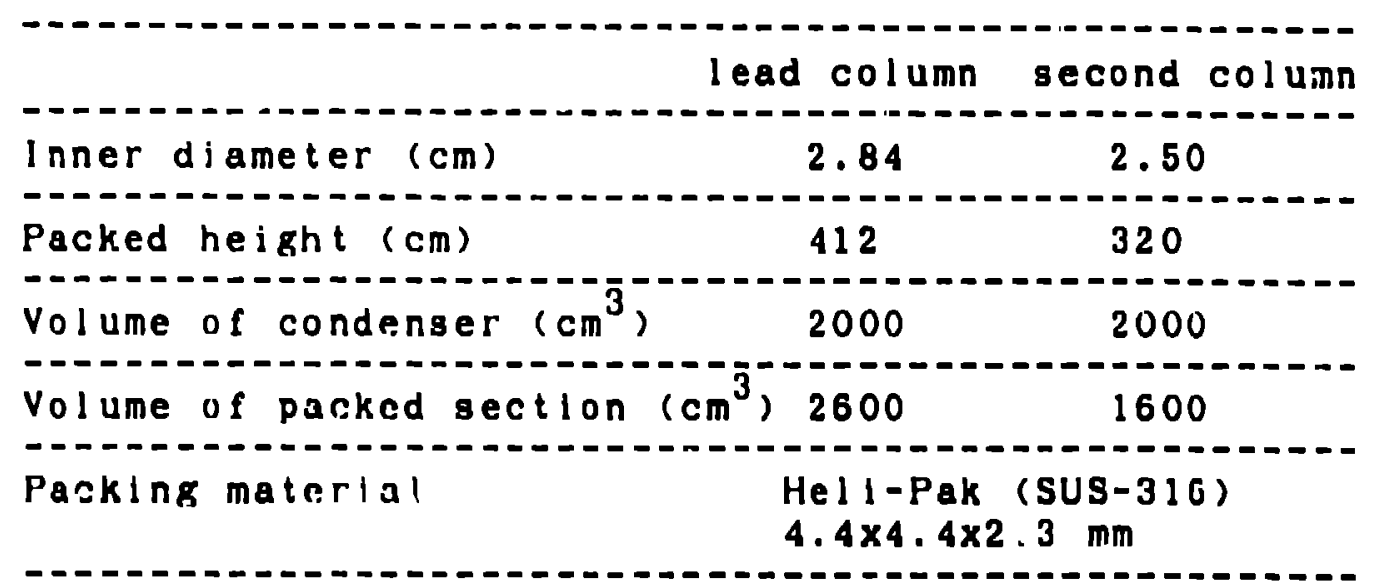


Tablc II Expcrimental and calculational conditions

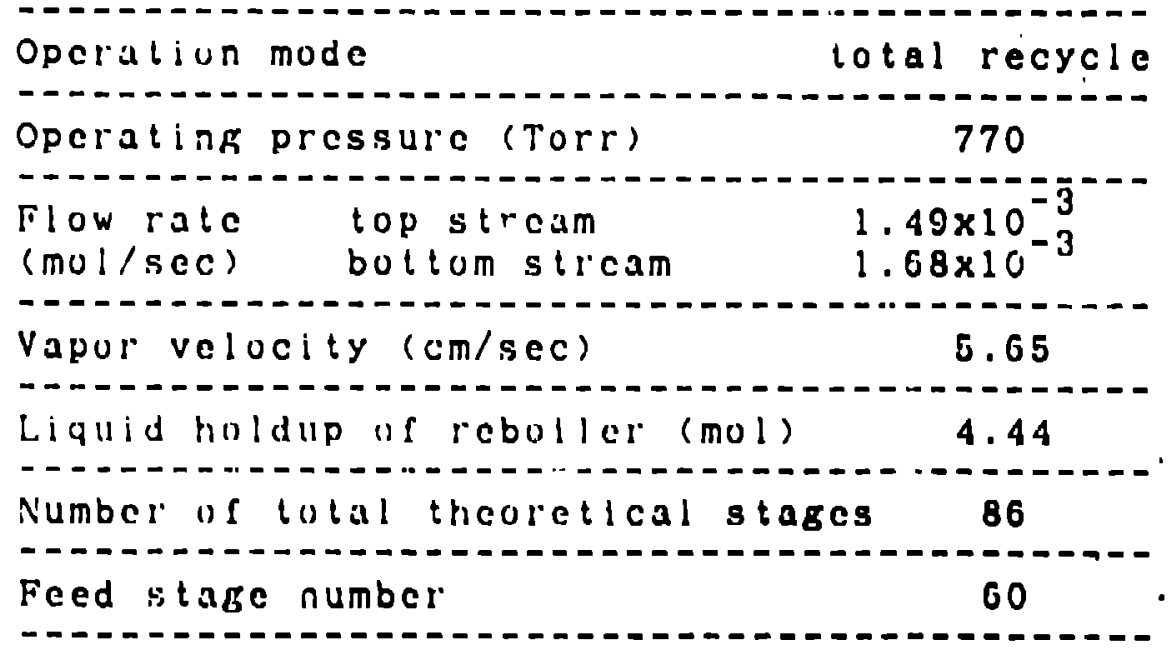




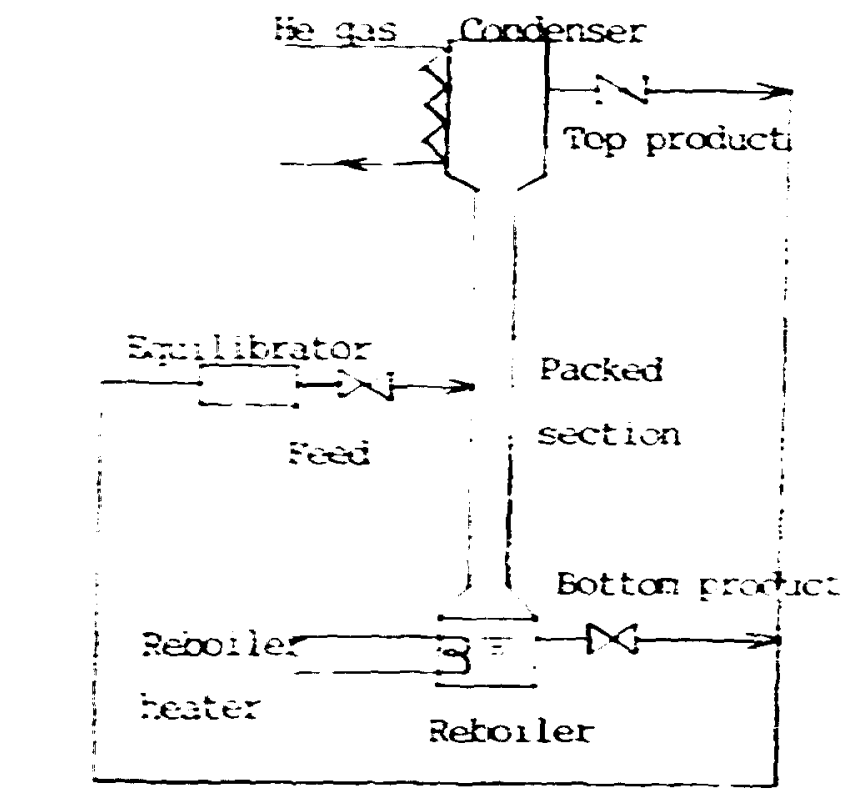

:Ig. 1 Conceptual flow diagram

for single column experiment

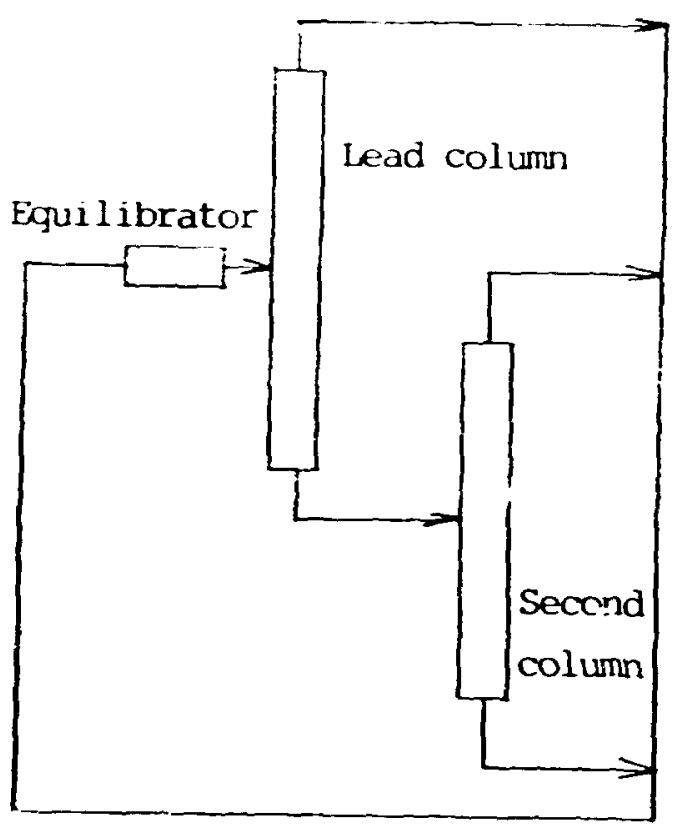

Fig.2 Configuration of cascade 


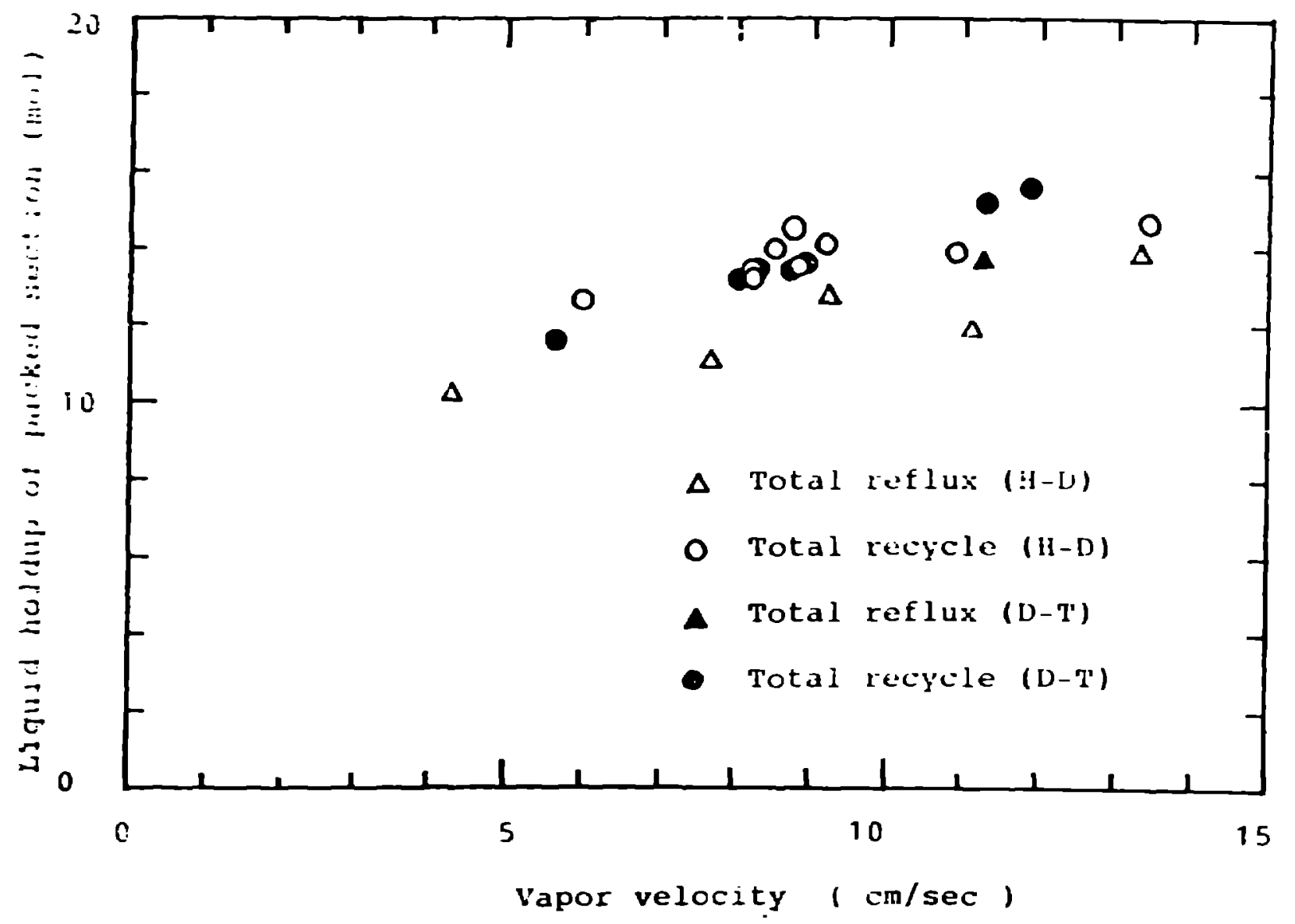

Fig. 3 Variation of liquid holdup in packed section with vapor velocity. 

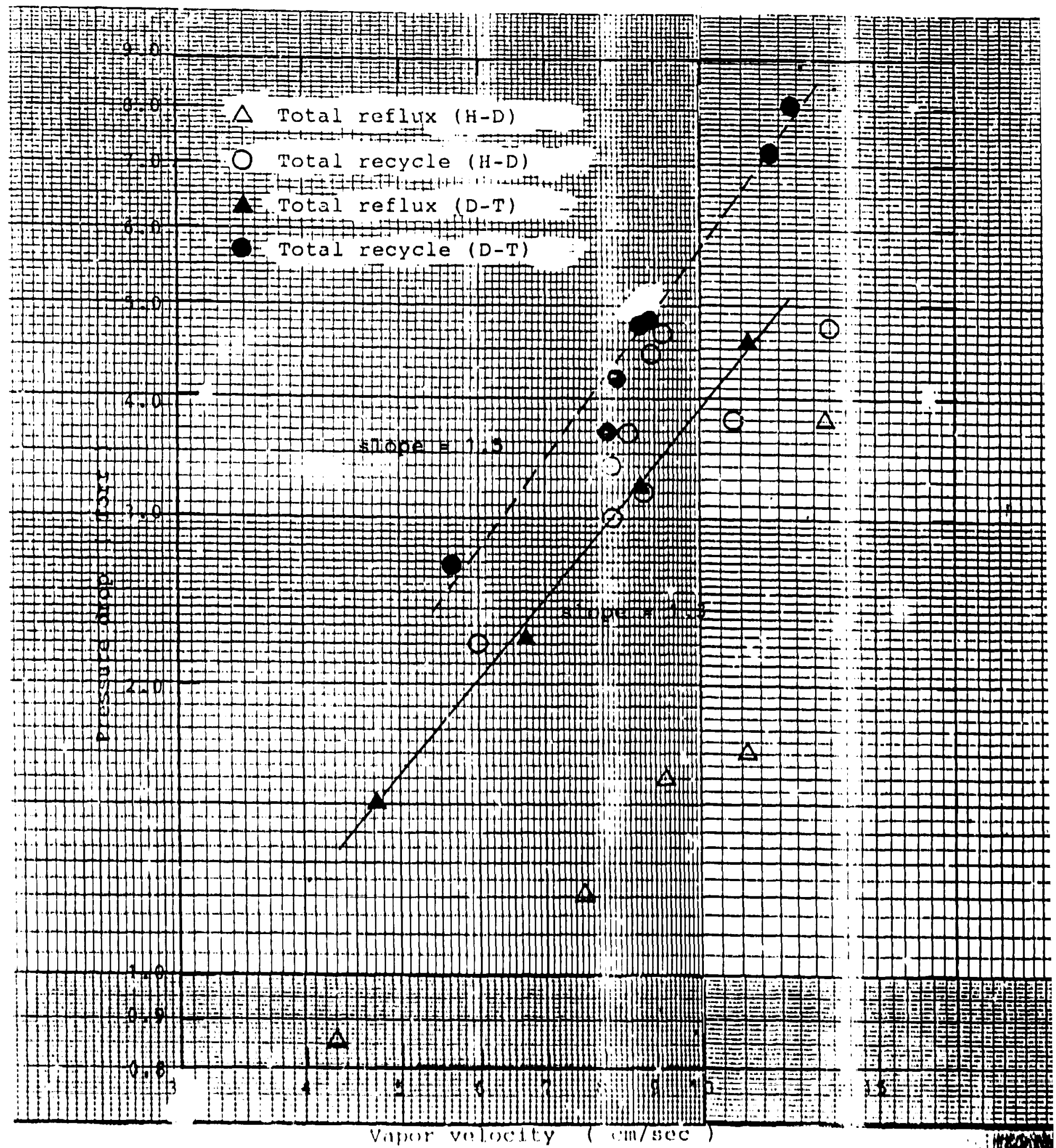

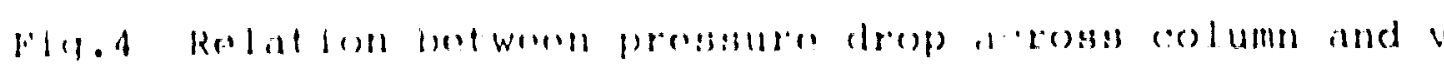




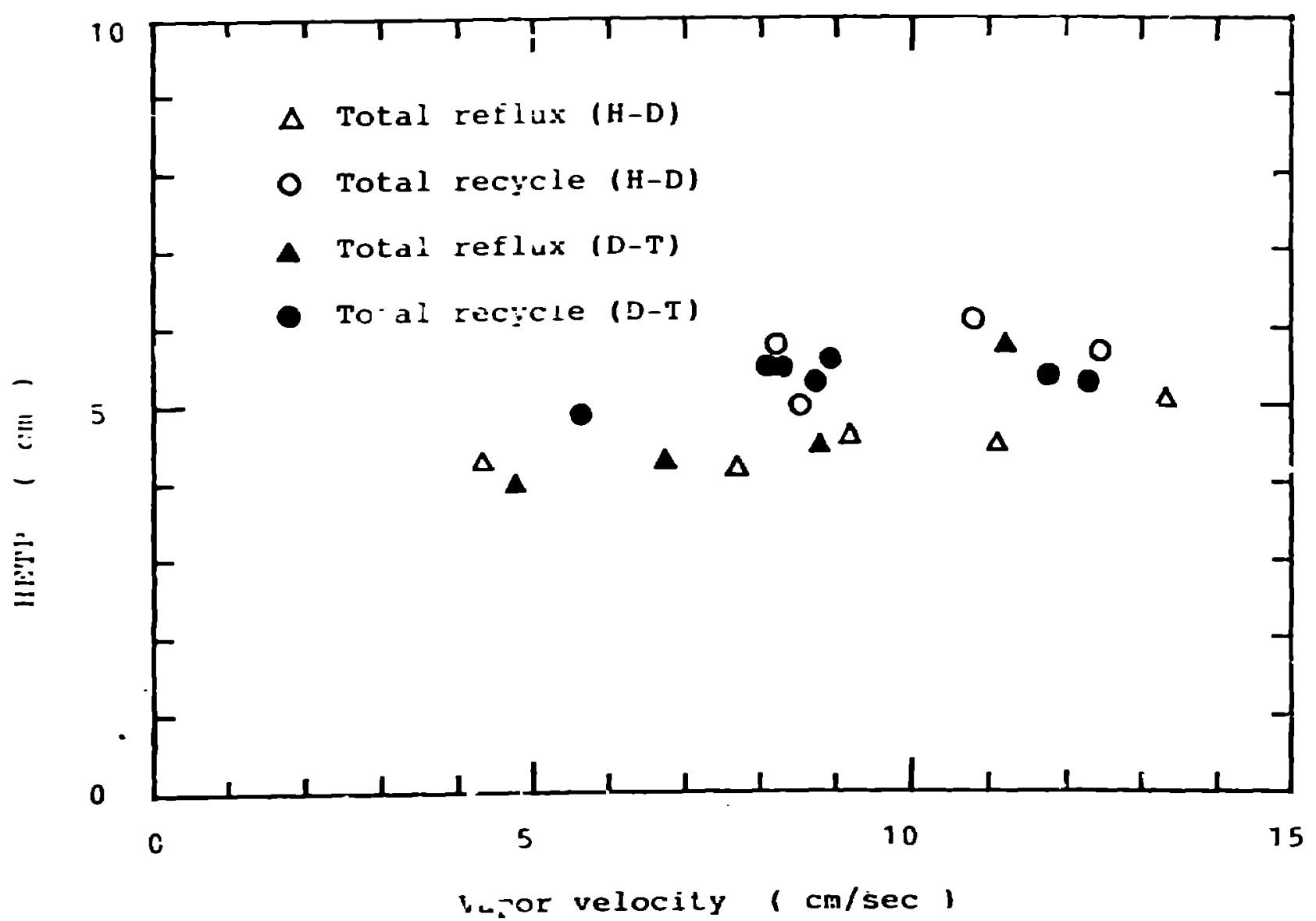

Fig. 5 Effect of yapor velocity on overall HETP value 


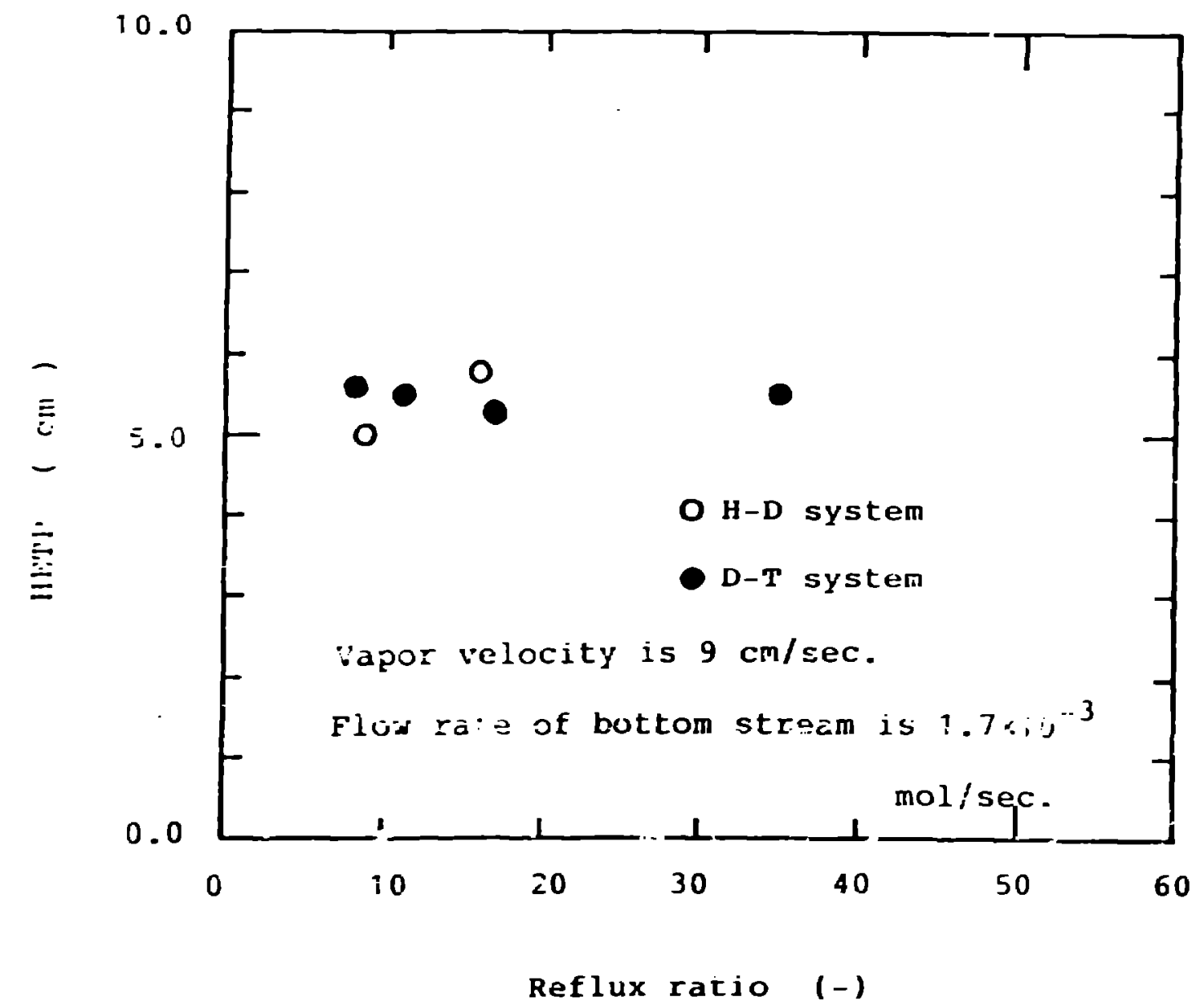

Fig. 6 Effect of reflux ratio on overall HETP value 


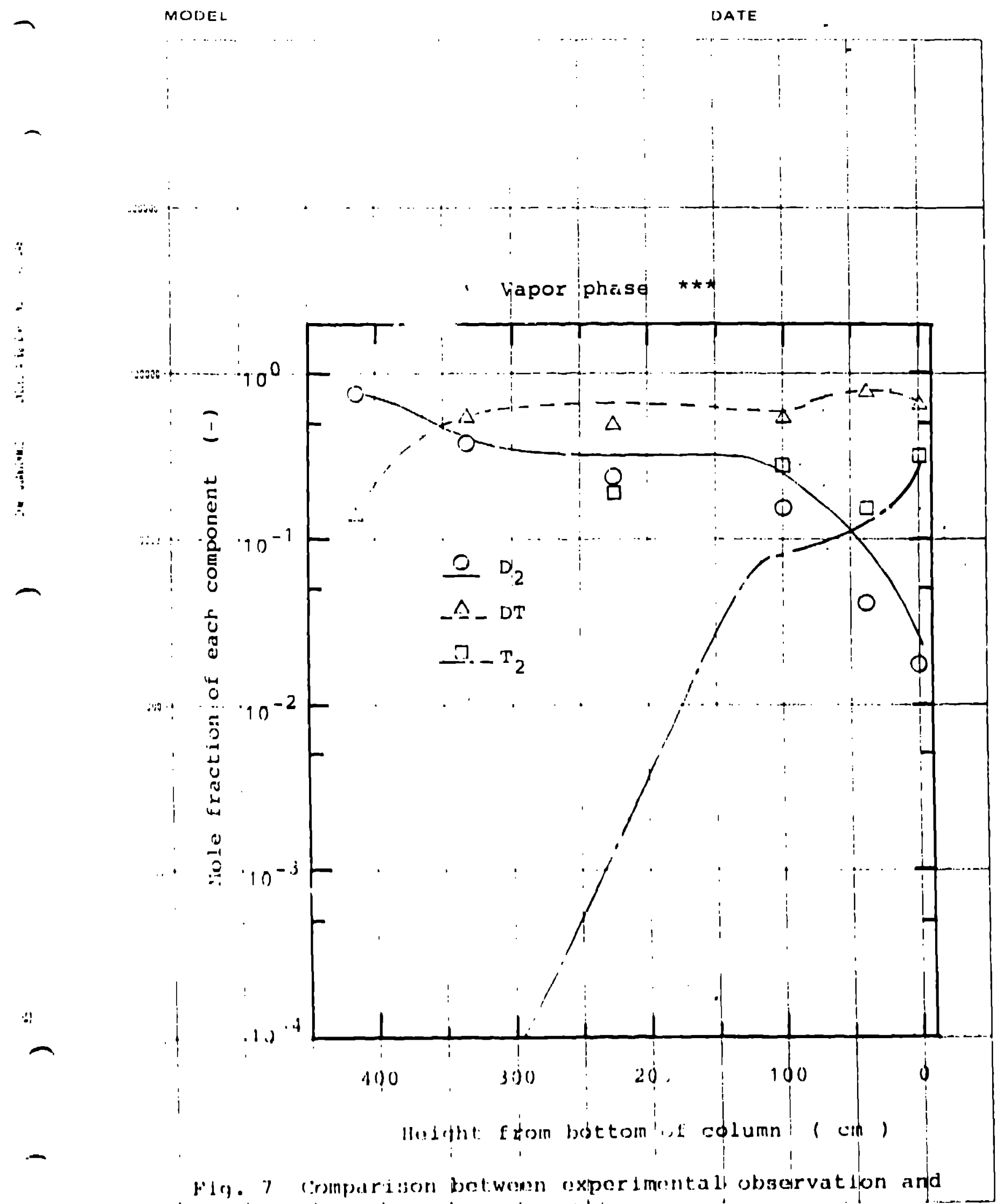

Fla. I Crmpariagon bet:wom experimental observation and adculational result for compostion distribution 